\title{
ГосуАарственная служба в правоохранительной сфере и ее основные признаки ${ }^{1}$
}

\author{
P. В. НАГОРНЫХ \\ Вологодский институт права и экономики ФСИН России, г. Вологда, Россий- \\ ская Федерация.
}

ORCID: https://orcid.org/0000-0002-4765-8550, e-mail: nagornikh-vipe@mail.ru

Ре ферат. Статья посвящена проблемам определения основных признаков государственной службы в правоохранительной сфере, ее места в механизме административно-правового регулирования. Целями работы являются рассмотрение государственной службы в правоохранительной сфере в качестве единой правовой категории, раскрытие ее характерных признаков и сущности как социальной системы, научная классификация ее составных элементов и раскрытие их административно-правового содержания.

Автором выделены основные функциональные признаки государственных органов, служба в которых является правоохранительной:

- государственно-властный характер деятельности;

- наделенность исполнительно-распорядительными (административными) полномочиями;

- особое функционально-целевое предназначение;

- применение специальных мер правового воздействия на основе использования методов убеждения и принуждения;

- особый правовой статус.

Обоснован вывод о том, что практическое решение вопроса об отнесении государственной службы в том или ином государственном органе к правоохранительной может быть осуществлено посредством законодательного определения понятия правоохранительной деятельности государства, правоохранительных функций государственных органов и системы государственных органов, осуществляющих правоохранительные функции.

Ключевые слова: государственная служба; административно-правовое регулирование; правоохранительная деятельность; правоохранительные функции; правовое принуждение.

12.00.14 - Административное право; административный процесс.

Для цитирования: Нагорных Р. В. Государственная служба в правоохранительной сфере и ее основные признаки. Пенитенциарная наука. 2020, т. 14, № 4 (52), с. 507-513. DOI 10.46741/2686-9764-2020-14-4-507-513.

\section{State Service in the Law Enforcement Sphere and Its Major Features ${ }^{2}$}

\section{ROMAN V. NAGORNYKH}

Vologda Institute of Law and Economics of the Federal PenitentiaryService of Russia, Vologda, Russian Federation

ORCID: https://orcid.org/0000-0002-4765-8550, e-mail: nagornikh-vipe@mail.ru

\footnotetext{
${ }^{1}$ Статья написана на основе материалов диссертации автора на соискание ученой степени доктора юридических наук «Административно-правовое регулирование государственной службы Российской Федерации в правоохранительной сфере», публикуется впервые.

${ }^{2}$ The paper is based on the materials of the author's Doctor of Sciences (Law) dissertation "Administrative and legal regulation of the state service of the Russian Federation in the law enforcement sphere", it is published for the first time.
} 
A bstract. The article investigates the main features of state service in the law enforcement sphere and the place of state service in administrative and legal regulation mechanism. The goals of the work are as follows: to consider state service in the law enforcement sphere as a single legal category, to reveal its essence and characteristic features as a social system, to provide a scientific classification of its constituent elements and disclose their administrative and legal content. We highlight the following main functional features of those state bodies the service in which can be calledlaw enforcement activity:state and power-based nature of activity, exercising executive and administrative powers, special functional and target purpose, application of special measures of legal influence based on the use of persuasion and coercion methods, and a special legal status. We conclude that practical solution to the question of classifying state service in a particular state body as law enforcement activity may be found through legislative definition of the concept of law enforcement activity of the state, law enforcement functions of state authorities, and the system of state authorities exercising law enforcement functions.

Key words: s tate service; administrative and legal regulation; law enforcement activity; law enforcement functions; legal enforcement.

12.00.14. - Administrative law; administrative process.

For citation: Nagornykh R.V. State service in the law enforcement sphere and its major features. Penitentiary Science, 2020, vol. 14, no. 4 (52), pp. 507-513. DOI 10.46741/2686-9764-2020-14-4-507-513.

Рассмотрение государственной службы в правоохранительной сфере в качестве единой правовой категории позволяет раскрыть ее характерные признаки и сущность как социальной системы, дать научную классификацию ее составных элементов и описать их административно-правовое содержание. Наиболее эффективное решение поставленных задач возможно на основе применения интегративного подхода, который позволяет не только выявить общие черты и признаки системы государственной службы в правоохранительной сфере, но и уяснить особенности ее элементов, их групп, объединяемых в отдельные подсистемы, а также определить ее неэтативные особенности [7], что имеет принципиальное значение с точки зрения формирования новой модели государственной службы в правоохранительной сфере.

Рассмотрение государственной службы в правоохранительной сфере как социальноправовой системы предполагает:

- исследование ее функциональной среды, выявление взаимозависимостей с другими социальными системами (системой государственной службы, правоохранительной системой, государством и обществом, функциональной средой);

- изучение ее внутренней структуры и содержания, составных элементов и связей между ними, а также их правового регулирования;

- выявление основных социально-гуманистических начал службы и их позитивации в действующем законодательстве.

На этой основе может быть дана общая характеристика системы государственной службы в правоохранительной сфере как единого социально-правового явления.
Государственная служба в правоохранительной сфере относится к разновидности профессиональной деятельности граждан на должностях в государственных органах, осуществляющих различные виды правоохранительной деятельности [9]. Сущность и содержание системы государственной службы в правоохранительной сфере, ее социальное назначение детерминированы прежде всего внешней средой функционирования, которая охватывает специфические общественные отношения, связанные с защитой интересов личности, общества и государства от различного рода угроз административно-деликтного, криминального, а также природного и техногенного характера. При этом в структуре правопорядка, то есть в структуре общественных отношений, урегулированных нормами права и охраняемых государством, можно выделить группу общественных отношений, имеющих особое социальное значение и охраняемых специальными правовыми мерами. Речь идет об общественных отношениях, охраняемых законодательством об административных правонарушениях и уголовным законодательством. На наш взгляд, именно рассмотрение законодателем отдельных видов общественных отношений в качестве объектов административно-правовой и уголовно-правовой защиты является основополагающим критерием понимания содержания и структуры как правоохранительной деятельности, так и государственной правоохранительной службы.

В общем виде внешняя функциональная среда правоохранительной деятельности может быть определена как совокупность различных общественных отношений, урегулированных нормами права и охраняемых 
специальными правовыми мерами и средствами на основе правовых методов убеждения и принуждения.

Функциональная среда правоохранительной деятельности состоит из особых групп общественныхотношений, имеющихнаивысшую социальную ценность и нуждающихся в усиленной защите со стороны государства, а именно из общественных отношений, правовая защита которых предусматривается особенными частями КоАП РФ и УК РФ. Данные общественные отношения имеют специфические объекты, охрана и защита которых осуществляются в рамках правоохранительной деятельности в ее узком понимании.

Исходя из анализа ст. 1.2 КоАП РФ и ст. 2 УК РФ, определяющих задачи законодательства об административных правонарушениях и уголовного законодательства, можно составить перечень объектов юридической защиты, являющихся приоритетными для государства и общества:

- личность (человек и гражданин), ее права и свободы;

- здоровье граждан;

- санитарно-эпидемиологическое благополучие населения;

- общественная нравственность;

- окружающая среда;

- установленный порядок осуществления государственной власти;

- общественный порядок и общественная безопасность;

- собственность;

- экономические интересы физических и юридических лиц, общества и государства;

- конституционный строй Российской Федерации;

- мир и безопасность человечества.

Именно необходимость защиты данных объектов обусловливает применение широкого спектра правовых мер профилактики, пресечения, обеспечения производства по делам, привлечения к ответственности, правовосстановления, которые в свою очередь определяют содержание правоохранительной деятельности государства и ее основные функции. Названные меры в соответствии с действующим законодательством выступают специфическими средствами охраны и защиты указанных нами объектов и не могут применяться для защиты других объектов правоотношений. В связи с этим в качестве основной функции правоохранительной деятельности государства может рассматриваться именно противодействие преступности и административным правонарушениям, общий совокупный объект которых и составляет, собственно говоря, предмет правоохранительной деятельности в ее узком понимании.

Основная правоохранительная функция государства может иметь различные подвиды. Так, К. Ф. Гуценко и М. А. Ковалев рассматривают в качестве таковых конституционный контроль; правосудие; прокурорский надзор; выявление, расследование и предупреждение правонарушений (преступлений); организационное обеспечение деятельности судов; обеспечение государственной и общественной безопасности; оказание юридической помощи [3, с. 8]. Во многом схожую позицию занимает В. П. Божьев, по мнению которого к правоохранительным функциям (деятельности) государства относятся конституционный контроль; осуществление правосудия; прокурорский надзор; оперативно-розыскная деятельность; выявление и раскрытие преступлений; обеспечение государственной безопасности; исполнение судебных решений; охранная деятельность и предупреждение преступлений и иных правонарушений; оперативно-розыскная деятельность; оказание квалифицированной юридической помощи [8, с. 21].

Обе точки зрения, безусловно, заслуживают внимания, однако требуют уточнения. Представляется, что к функциям, которые имеют непосредственное отношение к правоохранительной деятельности государственных органов в широком значении, можно отнести отправление правосудия; прокурорский надзор; борьбу с преступностью (либо противодействие преступности); защиту собственности; охрану общественного порядка; обеспечение личной, общественной и государственной безопасности; исполнение решений о привлечении к юридической ответственности судебных и иных органов в рамках производства по уголовным делам и делам об административных правонарушениях.

Функции конституционного контроля и оказания юридической помощи, на наш взгляд, не входят непосредственно в предмет правоохранительной деятельности в ее узком понимании, а присущи правоохранительной деятельности в широком, общегосударственном значении. При этом функции отправления правосудия и прокурорского надзора в силу своей специфики, обусловленной наличием особого конституционноправового регулирования и действием специального законодательства, также должны рассматриваться за пределами правоохранительной деятельности в ее узком значении. 
В целом к правоохранительной деятельности в узком понимании следует отнести борьбу с преступностью, включая профилактику правонарушений, а также раскрытие (выявление) и расследование преступлений; охрану общественного порядка; обеспечение личной и общественной безопасности, исполнение решений судебных и контролирующих органов. Названные правоохранительные функции осуществляются специализированными правоохранительными органами исполнительной власти, которые в свою очередь также образуют соответствующую отраслевую правоохранительную подсистему.

Важно отметить, что в настоящее время система правоохранительных органов государства (правоохранительная система) в организационно-правовом аспекте сформирована наиболее отчетливо и ее функционально-целевая идентификация в системе государственного управления не вызывает серьезных споров. Многие исследователи, говоря о правоохранительной системе государства в узком значении, имеют в виду прежде всего органы судебной власти, органы прокуратуры и непосредственно правоохранительные органы исполнительной власти. При этом застарелой проблемой является законодательная неопределенность основных понятий, относящихся к правоохранительной деятельности, ее целей, задач, функций, системы и т. д. В этой связи сложно возразить В. М. Исаенко, обосновавшему необходимость принятия федерального закона «О правоохранительной деятельности» [5, с. 163].

На наш взгляд, наиболее точную классификацию государственных органов, входящих в правоохранительную систему государства, предлагает В. В. Черников. По его мнению, в ее структуре наряду с органами, обладающими особым конституционноправовым статусом (суд, прокуратура, а в настоящее время и Следственный комитет Российской Федерации (СК РФ)), следует особо выделять непосредственно правоохранительные органы исполнительной власти, осуществляющие правоохранительную деятельность в ее узком значении [11, с. 5].

Таким образом, понимая под системой совокупность элементов и отношений, закономерно связанных друг с другом в единое целое, которое обладает особенными интегративными свойствами, отсутствующими у отдельных элементов и отношений, можно дать следующее определение правоохранительной системы государства: это совокупность государственных органов, наделенных в установленном порядке полномочиями в области осуществления правосудия, прокурорской и следственной деятельности, а также исполнительно-распорядительными полномочиями в сфере защиты прав и интересов граждан от противоправных посягательств, борьбы с преступностью, охраны общественного порядка, обеспечения личной и общественной безопасности, исполнения решений о привлечении к юридической ответственности посредством применения правовых мер убеждения и принуждения, а также иных социальных функций в рамках осуществления административной, оперативно-розыскной, уголовно-процессуальной и уголовно-исполнительной деятельности. Особое место в структуре правоохранительной системы государства занимают правоохранительные органы исполнительной власти, которые специализируются на осуществлении правоохранительной деятельности в ее узком понимании.

Правоохранительная деятельность определяет не только содержание и структуру правоохранительной системы государства, но и содержание государственной правоохранительной службы. На основе анализа правоохранительных функций государства представляется возможным определить виды государственной службы в правоохранительной сфере. Исходным постулатом для такой классификации может послужить тезис о том, что система государственной правоохранительной службы производна от правоохранительной деятельности государства.

Следует отметить, что в настоящее время правоохранительные функции закреплены за различными государственными органами, которые имеют отличающийся правовой статус и не всегда однозначно идентифицируются с определенной ветвью государственной власти. Особенно ярко эта проблема просматривается в отношении органов прокуратуры и следственных органов (в части органов СК РФ), обладающих особым правовым статусом.

По нашему мнению, относительно определения правового статуса органов прокуратуры следует согласиться с точкой зрения А. М. Тарасова, утверждавшего, что «прокуратура, осуществляя прокурорский надзор и являясь самостоятельным и независимым государственным контрольно-надзорным органом, в том числе и за правоохранительной деятельностью, представляет собой самостоятельный государственный орган, не относящийся ни к одной из ветвей власти, 
перечисленных в ст. 10 Конституции Российской Федерации» [10, с. 34-38].

В специальных исследованиях, посвященных анализу мировой практики определения правового положения органов прокуратуры в различных государствах, приводятся примеры их отнесения к различным ветвям власти [4]. В современной России органы прокуратуры по кругу решаемых задач и реализации ряда исполнительно-распорядительных функций, безусловно, относятся к правоохранительным и близки по характеру своей деятельности к правоохранительным органам исполнительной власти. Однако данные органы имеют особый конституционно-правовой статус, что обусловлено функциями органов прокуратуры, обеспечивающих верховенство закона, единство и укрепление законности, защиту прав человека и гражданина, а также охраняемых интересов общества и государства [2, с. 7]. В связи с этим в настоящее время в органах прокуратуры сложился особый вид государственной службы, в основу которой положен порядок прохождения, присущий гражданской государственной службе. Это обстоятельство, однако, не исключает возможности отнесения службы в органах прокуратуры в силу ее правоохранительной специфики к правоохранительной службе в качестве разновидности последней. При этом следует обратить внимание и на то обстоятельство, что реализация функции расследования дел о преступлениях как особой правоохранительной функции прокуратуры, до недавнего времени относившейся к ведению органов прокуратуры, сегодня передана СК РФ [6].

Не останавливаясь подробно на анализе статуса прокуратуры и дальнейших перспектив развития данного ведомства ввиду того, что эти проблемы образуют самостоятельное направление современных научных исследований, следует обратить внимание на неоднозначность и многовариантность возможных путей практического разрешения соответствующих вопросов. Общим направлением развития органов прокуратуры в России как самостоятельного контрольнонадзорного органа и органа, поддерживающего обвинение в суде, защищающего права и свободы граждан от противоправных посягательств, должны стать постепенное избавление от несвойственных функций, прежде всего в сфере исполнительно-распорядительной деятельности, и поэтапная передача их в ведение правоохранительных органов исполнительной власти, например Минюста либо МВД России. Вполне логичным эта- пом в реализации этого процесса является и создание специального федерального государственного органа, осуществляющего полномочия в сфере уголовного судопроизводства, - СК РФ, государственная служба в котором обладает своей спецификой, позволяющей считать ее государственной службой в правоохранительной сфере.

Следует подробнее остановиться на проблеме государственной службы в органах СК РФ, которая сегодня, по сути, является идентичной службе в органах прокуратуры. Вместе с тем органы СК РФ выполняют правоохранительные функции в области расследования преступлений, которые в настоящее время осуществляются и иными федеральными органами исполнительной власти (МВД, ФСБ России). В силу этого целесообразно вести речь о перспективе отнесения органов СК РФ именно к системе органов исполнительной власти. Следовательно, и служба в органах СК РФ должна рассматриваться как разновидность государственной службы в правоохранительной сфере органов исполнительной власти. Такое понимание проблемы позволяет, по нашему мнению, решить важнейшую государственную задачу - создать единую систему государственной службы в правоохранительной сфере органов исполнительной власти как особую подсистему государственной службы в правоохранительной сфере.

Таким образом, отнесение органов СК РФ (с последующим объединением в рамках данного федерального государственного органа всех следственных органов России) к органам исполнительной власти позволит, с одной стороны, решить вопрос об окончательном формировании единого федерального органа, осуществляющего функции расследования преступлений, а с другой определить статус государственной службы в органах предварительного расследования как федеральной государственной службы в правоохранительной сфере органов исполнительной власти.

Анализ современного состояния правоохранительной системы позволяет выделить следующие основные функциональные признаки государственных органов, служба в которых является правоохранительной:

- государственно-властный характер деятельности. В рассматриваемом нами случае речь идет именно о государственных органах, обладающих властными полномочиями в области правоохранительной деятельности. Это, прежде всего, органы 
государства, которые специализируются на осуществлении правоохранительной функции, что составляет основное направление их деятельности;

- наделенность исполнительно-распорядительными (административными) полномочиями. По нашему мнению, среди государственных органов, осуществляющих правоохранительную деятельность, особое место занимают органы исполнительной власти: именно они образуют основной массив правоохранительных органов государства и выполняют наиболее значительный объем правоохранительных функций. Следует отметить, что наряду с правоохранительными органами исполнительной власти существуют и другие органы, выполняющие государственные правоохранительные функции, - органы конституционного контроля, прокурорского надзора, правосудия [1, с. 30], которые имеют специальный правовой (в ряде случаев конституционно-правовой) статус и в которых, как нам представляется, должны быть предусмотрены специальные виды государственной службы;

- особое функционально-целевое предназначение. Правоохранительные органы, государственная служба в которых относится к службе в правоохранительной сфере, имеют особое функционально-целевое предназначение. В первую очередь они выполняют функции в области борьбы с преступностью, охраны общественного порядка, обеспечения личной и общественной безопасности;

- применение специальных мер правового воздействия на основе использования методов убеждения и принуждения [12, c. 29], а также специальных юридических процедур [13]. Собственно говоря, этот признак является ключевым в раскрытии содержания правоохранительной деятельности и позволяет вычленить правоохранительные органы из общего массива органов государства. В научной литературе к таким правовым мерам убеждения и принуждения относятся профилактика и предупреждение правонарушений, пресечение правонарушений, процессуальное обеспечение производства по делам о правонарушениях, привлечение виновных лиц к различным видам юридической ответственности за совершенные правонарушения, восстановление нарушенного права. Важнейшими, на наш взгляд, признаками относимости конкретного государственного органа к правоохранительным являются его вооруженность и, соответственно, наделение его служащих полномочиями по применению мер физического принуждения к пра- вонарушителям, а именно физической силы, специальных средств и оружия;

- специальный правовой статус. Все органы, наделенные правоохранительными функциями, имеют особый правовой статус. Прежде всего это выражается в нормативном закреплении компетенции по применению правовых мер убеждения и принуждения в различных сферах правоохранительной деятельности, в том числе административной, административно-юрисдикционной, оперативно-розыскной, уголовно-процессуальной, исполнительной (уголовно-исполнительной и административно-исполнительной, под которой мы понимаем деятельность в области исполнения решений судов и иных органов административной юрисдикции по делам об административных правонарушениях). Особенности правового положения правоохранительных органов предопределяют административно-правовой статус служащих государственной службы, их права, обязанности, ответственность.

Правовое положение государственных органов, наделяемых правоохранительными функциями, закрепляется действующим административным законодательством. При этом наряду с общими актами, регламентирующими непосредственно административно-правовой статус указанных органов, их деятельность регулируется и значительным массивом законодательных и подзаконных актов в рамках отдельных видов правоохранительной деятельности, прежде всего административной, оперативно-розыскной, уголовно-процессуальной и исполнительной (уголовно-исполнительной, административно-исполнительной).

Таким образом, наличие названных системных (функционально-целевых) признаков является основанием для отнесения указанных государственных органов к правоохранительным и, следовательно, службы в них к соответствующему виду государственной службы в правоохранительной сфере, поскольку подобная государственная служба является производной от компетенции правоохранительных органов.

Вместе с тем практическое решение вопроса об отнесении государственной службы в том или ином государственном органе к правоохранительной может быть осуществлено посредством законодательного определения понятия правоохранительной деятельности государства, правоохранительных функций государственных органов и системы государственных органов, осуществляющих правоохранительные функции. 


\section{СПИСОК ЛИТЕРАТУРЫ}

1. Братко, А. Г. Правоохранительная система (вопросы теории) : автореферат диссертации на соискание ученой степени доктора юридических наук / Братко Александр Григорьевич. - Москва, 1992. - 41 с.

2. Велиев, И. В. Прокуратура в системе органов публичной власти: опыт сравнительного исследования по материалам Азербайджанской Республики, Российской Федерации и Республики Казахстан : автореферат диссертации на соискание ученой степени доктора юридических наук / Велиев Исахан Вейсал оглы. - Москва, 2006.

3. Гуценко, К. Ф. Правоохранительные органы / К. Ф. Гуценко, М. А. Ковалев. - Москва : Зерцало-М, 2010. 496 с. - ISBN 978-5-94373-164-8.

4. Додонов, В. Н. Прокуратура в России и за рубежом. Сравнительное исследование / В. Н. Додонов, В. Е. Крутских ; под редакцией С. И. Герасимова. - Москва : НОРMA, 2001. - 192 с. - ISBN 5-89123-534-X.

5. Исаенко, В. М. Организация правоохранительной деятельности / В. М. Исаенко // Актуальные проблемы российского права. - 2015. - № 9 (58) - - С. 162-166.

6. О Следственном комитете Российской Федерации : Федеральный закон от 28.12.2010 № $403-$ Ф3 // Собрание законодательства Российской Федерации. - 2011. - № 1. - Ст. 15.

7. Оботурова, Н. С. Проблема прав человека в контексте идей гуманизма и трансгуманизма / Н. С. Оботурова // Пенитенциарная наука. - 2020. - Том 14, № 2. - С. 155-161.

8. Правоохранительные органы России : учебник для вузов / под общей редакцией В. П. Божьева, Б. Я. Гаврилова. 6-е изд., перераб. и доп. - Москва : Юрайт, 2019. - 296 с. - ISBN 978-5-534-05933-5.

9. Стелина, Я. Теоретические концепции института государственной службы / Я. Стелина // Правоприменение. 2019. - Том 3, № 2. - C. 21-30. - DOI 10.24147/2542-1514.2019.3(2).21-30.

10. Тарасов, А. М. Правоохранительная деятельность: ее понятие и сущность / А. М. Тарасов // Российский следователь. - 2002. - № 4. - С. 34-38.

11. Черников, В. В. Судебные, правоохранительные и контрольные органы России / В. В. Черников. - Москва : Проспект, 2002. - 686 с. - ISBN 5-902171-85-7.

12. Числов, А. И. Профессиональная правоохранительная деятельность (теоретико-правовое исследование) : автореферат диссертации на соискание ученой степени доктора юридических наук / Числов Александр Иванович. Санкт-Петербург, 2000. - 48 с.

13. Bocharova, N. Administrative justice: comparative and russian context / N. Bocharova // BRICS law journal. - 2016. Volume 3, no. 3. - Pp. 143-151. - DOI 10.21684/2412-2343-2016-3-3-143-151.

\section{REFERENCES}

1. Bratko A.G. Pravookhranitel'naya sistema (voprosy teorii): avtoreferat dissertatsii na soiskanie uchenoi stepeni doktora yuridicheskikh nauk [Law enforcement system (theoretical issues): Doctor of Sciences (Law) dissertation abstract]. Moscow, 1992. $41 \mathrm{p}$.

2. Veliev I.V. Prokuratura v sisteme organov publichnoi vlasti: opyt sravnitel'nogo issledovaniya po materialam Azerbaidzhanskoi Respubliki, Rossiiskoi Federatsii i Respubliki Kazakhstan: avtoreferat dissertatsii na soiskanie uchenoi stepeni doktora yuridicheskikh nauk [The prosecutor's office in the system of public authorities: the experience of a comparative study based on the materials of the Republic of Azerbaijan, the Russian Federation and the Republic of Kazakhstan: Doctor of Sciences (Law) dissertation abstract]. Moscow, 2006. 34 p.

3. Gutsenko K.F., Kovalev M.A. Pravookhranitel'nye organy [Law enforcement agencies]. Moscow: Zertsalo-M, 2010. 496 p. 4. Dodonov V.N., Krutskikh V.E. Prokuratura v Rossii i za rubezhom: sravnitel'noe issledovanie [The prosecutor's office in Russia and abroad: a comparative study]. Moscow, 2001. 192 p.

5. Isaenko V.M. Organization of law enforcement. Aktual'nye problemy rossiiskogo prava=Actual Problems of Russian Law, 2015, no. 9 (58), pp. 162-166. (In Russ.).

6. Federal Law of December 28, 2010 No. 403-FZ "On the Investigative Committee of the Russian Federation". In: Sobranie zakonodatel'stva Rosiiskoi Federatsii [Collection of legislation of the Russian Federation]. 2011. No. 1. Art. 15. (In Russ.). 7. Oboturova N.S. The problem of human rights in the context of the ideas of humanism and transhumanism. Penitentsiarnaya nauka=Penitentiary Science, 2020, vol. 14, pp. 155-161. (In Russ.).

8. Bozh'evV.P., Gavrilov B.Ya. (Eds.). Pravookhranitel'nye organy Rossii: uchebnik dlya vuzov[Law enforcement agencies of Russia: textbook for universities]. Sixth edition, revised and supplemented. Moscow: Izdatel'stvo Yurait, 2019. 296 p. 9. Stelina J. Theoretical concepts of the law of civil servants. Pravoprimenenie = Law Enforcement Review, 2019 , vol. 3 , no. 2, pp. 21-30. DOI 10.24147/2542-1514.2019.3(2).21-30. (In Russ.).

10. Tarasov A.M. Law enforcement activity: its concept and essence. Rossiiskii sledovatel'=Russian Investigator, 2002, no. 4, pp. 34-38. (In Russ.).

11. Chernikov V.V. Sudebnye, pravookhranitel'nye i kontrol'nye organy Rossii [Judicial, law enforcement and control agencies of Russia]. Moscow: Prospekt, 2002. 686 p.

12. Chislov A.I. Professional'naya pravookhranitel'naya deyatel'nost' (teoretiko-pravovoe issledovanie): avtoreferat dissertatsii na soiskanie uchenoi stepeni doktora yuridicheskikh nauk [Professional law enforcement (theoretical and legal research): Doctor of Sciences (Law) dissertation abstract]. Saint Petersburg, 2000. 48 p.

13. Bocharova N. Administrative justice: comparative and Russian context. BRICS Law Journal, 2016, vol. 3, no. 3, pp. 143-151. DOI 10.21684/2412-2343-2016-3-3-143-151.

\section{СВЕДЕНИЯ ОБ АВТOPE / INFORMATION ABOUT THE AUTHOR}

РОМАН ВАДИМОВИЧ НАГОРНЫХ - ДОКТор юрИдИ ческих наук, доцент, почетный работник высшего проФессионального образования Российской Федерации, профессор кафедры административно-правовых дисциплин юридического факультета Вологодского института права и экономики ФСИН России, г. Вологда, Российская Федерация. ORCID: https://orcid.org/00000002-4765-8550, e-mail: nagornikh-vipe@mail.ru
ROMAN V. NAGORNYKH - Doctor of Sciences (Law), Associate Professor, Honorary Worker of Higher Professional Education of the Russian Federation, Professor of the Department of Administrative and Legal Disciplines, Vologda Institute of Law and Economics of the Federal Penitentiary Service of Russia, Vologda, Russian Federation. ORCID: https://orcid.org/0000-0002-4765-8550, e-mail: nagornikh-vipe@mail.ru 